\title{
POBREZA Y EJERCICIO DE LA DEMOCRACIA
}

JORGE ARMANDO ROJAS DE LUNA

Estudiante de la Licenciatura en Sociología/UAA

Silvia M. Bénard Calva, Pobreza y participación social en México. Una aproximación desde el caso de Aguascalientes, Aguascalientes, Centro de Investigaciones y Estudios Multidisciplinarios de Aguascalientes-Sistema de Investigación Miguel Hidalgo, 1999.

El libro que nos ofrece Silvia Bénard es una propuesta original para reflexionar sobre la relación que guardan la construcción de la democracia y la participación de los sectores populares en el terreno de la política, de la economía y en el complejo entramado de las relaciones sociales. Por lo general, los estudios sobre pobreza analizan el fenómeno desde perspectivas teóricas y metodológicas que prescinden de los sujetos que encarnan esa situación. En estos estudios se concibe a los "pobres" como sim- ples receptores de los cambios políticos y de las acciones que el gobierno realiza para combatir la pobreza. $\mathrm{La}$ propuesta de Silvia Bénard da un giro a la concepción que se tiene tanto de los "pobres" como de la democracia misma. En este sentido, concibe a los "pobres" como ciudadanos y actores sociales clave que participan desde sus comunidades a través de grupos o instituciones intermedias en las decisiones que toman lo que Giddens llama "sistemas expertos" de una sociedad. Por consecuencia, la democracia es entendida en un sentido amplio y no la reduce al mero ejercicio de los derechos políticos en las contiendas electorales, sino como "la participación ciudadana en los ámbitos social y económico".

Entonces, si se concibe a la democracia no sólo desde su dimensión 
política, sino también desde su dimensión social, ¿̇cuál sería el vínculo entre ambas dimensiones de la democracia? O lo que es lo mismo, ¿cómo hacer posible la participación de los "pobres" en un proyecto democrático con tales características? Al parecer, una alternativa sería la creación de espacios sociales intermedios en los que sea posible la interacción entre el gobierno y los ciudadanos. En este contexto, la intención de la autora es hacer explícita la preocupación por construir espacios o instituciones intermedias flexibles que constituyan un puente entre el gobierno en sus tres niveles -federal, estatal y municipal- y los ciudadanos en su carácter de individuos. La interacción de estos espacios intermedios y el gobierno generaría, entonces, un Estado democrático y una sociedad más incluyente y equitativa.

Para la autora, la creación de esos vínculos entre la sociedad y el gobierno sería una alternativa viable para superar la desigualdad social que existe en México. El caso de Aguascalientes representa un ejemplo de ese intento por construir una mejor democracia representativa y participativa. A lo largo de su investigación, Silvia Bénard nos muestra la interacción que ha existido entre los grupos sociales y el gobierno en el estado de Aguascalientes desde que el gobiemo federal promovió la participación ciudadana a través de diferentes programas que organizaban a los ciudadanos en torno a ciertos esquemas como PRONASOL y los Comités de Solidaridad, los Talleres de Planeación Participativa, los Talleres de Participación Social, hasta llegar a los Comités de Colonos que fueron creados por la primera administración panista en la historia política de la ciudad capital (1996-1998).

Los datos que proporciona la autora para entender la relación entre democracia y pobreza, se derivan de entrevistas abiertas realizadas a personajes que han participado en esta nueva relación'entre el gobiemo y la ciudadanía. Esto permite entender la interacción entre esos grupos intermedios de participación ciudadana y el gobierno, no sólo desde los discursos triunfalistas de los de arriba, sino también desde los discursos que generan los ciudadanos que se comprometen a trabajar por su comunidad y que por lo general no tienen espacios para expresar sus experiencias. A través de la confrontación de ambas visiones de la realidad, es posible identificar las resistencias que 
enfrenta la participación ciudadana en Aguascalientes. Si nos quedamos con lo que dice el discurso oficial, pensaríamos de inmediato que la participación ciudadana ha triunfado en Aguascalientes. En el texto de Silvia Bénard, podemos leer las voces de los gobernantes haciendo referencia a la necesidad de incrementar la participación, a la posibilidad de su concreción para una sociedad democrática, etcétera. Casi no se leen voces que explícitamente se opongan a la participación. Sin embargo, la presente investigación nos muestra que la realidad no pasa solamente por los discursos y que en los hechos, los avances en la participación comunitaria exhiben una gran brecha con respecto a las declaraciones oficiales. La investigación de Silvia Bénard muestra que en algunas ocasiones los llamados a participar no se plasmaron en la apertura efectiva de puertas, sino que más bien hubo algunas experiencias iniciadas con amplias promesas pero que se quedaron en el "título" inicial, dando lugar a una que otra frustración pronunciada por las comunidades.

La investigación también nos muestra los logros obtenidos por las comunidades bajo los distintos esquemas de participación ciudadana y las expectativas que el trabajo comunitario ha despertado en los ciudadanos involucrados. De esta forma, un espacio intermedio que había sido proyectado desde arriba, sólo para propiciar la participación comunitaria en la gestión de los recursos públicos, puede ampliar las posibilidades de participar a otros ámbitos como el de la integración social y el sentido de pertenencia a una comunidad urbana o rural. Podemos interpretar las acciones emprendidas por esas organizaciones de colonos como la expresión de una voluntad que busca la integración social a través de la integración a la ciudad. Los colonos procuran proveerse de un hábitat que les permita organizar la vida familiar e individual a partir del acceso al medio urbano, en torno al cual gira casi la totalidad de la vida cotidiana. Pero, a su vez, el lugar permitiría a los individuos adquirir un sentido de pertenencia y de identidad. Estos últimos aspectos constituyen parte de las conclusiones derivadas del estudio de caso y abren nuevos caminos a la investigación sobre la participación ciudadana.

Por todo lo anterior, el libro que reseñamos constituye un novedoso acercamiento al fenómeno de la pobreza y a la relación que guarda con el ejercicio de la democracia. 
